\title{
Climate Extremes along the Mining Chain over the Eastern Amazon: Projections to 2050
}

\author{
Claudia Priscila Wanzeler da Costa*, Douglas da Silva Ferreira, Nikolas Jorge Carneiro \\ Instituto Tecnológico Vale, Belem, Brazil \\ Email: ^claudia.costa@itv.org, douglas.silva.ferreira@itv.org, nikolas.carneiro@itv.org
}

How to cite this paper: da Costa, C.P.W., da Silva Ferreira, D. and Carneiro, N.J. (2021) Climate Extremes along the Mining Chain over the Eastern Amazon: Projections to 2050. Atmospheric and Climate Sciences, 11, 125-147.

https://doi.org/10.4236/acs.2021.111009

Received: September 16, 2020

Accepted: January 10, 2021

Published: January 13, 2021

Copyright () 2021 by author(s) and Scientific Research Publishing Inc. This work is licensed under the Creative Commons Attribution International License (CC BY 4.0).

http://creativecommons.org/licenses/by/4.0/

\section{Abstract}

The mineral industry is of great importance for the economy and for the development of Brazil. However, climate change further accentuates the impacts caused by extreme weather and climate events on the logistics and operation processes of the mineral production chain (from the mine to the port). In order to reduce these effects, it is essential to have information about the future climate that will help this economic sector to carry out better long-term planning of its activities. However, the current scientific literature still lacks studies with this approach applied to the mineral industry. Therefore, the purpose of this study was to evaluate the future seasonal patterns of climate extremes in eastern Amazonia, exploring their impacts on the mineral production chain in the near future (2019-2050). To categorize the dry and rainy climate extremes, the Standard Precipitation Index (SPI) was calculated for the precipitation data series of Climate Prediction Center (CPC) observations and the PRECIS regional modeling system, considering the IPCC RCP4.5. The 1981-2005 period was defined as the present climate and used to assess the performance of the modeling system in reproducing the extremes. The analyses were based on the relative frequency of the categories of dry and rainy extremes. The performance evaluation of PRECIS showed that it had better accuracy in representing seasonal extremes of drought than extremes of rain. Along the mineral chain in eastern Amazonia, its accuracy was better over the port region, except for the dry extremes experienced from June to August (JJA), and from December to February (DJF) and March to May (MAM) for rainy extremes. The analysis of the frequency of occurrence of these events for the future indicates a greater probability of rain extremes along the mineral chain compared to another category of extremes. In addition, JJA will be the most suitable period to optimize operational processes in eastern Amazonia, as extremes are less likely to occur. On the other hand, the greater probability of extreme rain events from September through to November (SON) and MAM make these two periods less suitable for activity in 
the mining regions and areas north of the railway. The results of this study suggest an increasing risk to the processes of the mineral chain until 2050 associated with the occurrence of climate extremes, since it is susceptible to adverse weather conditions.

\section{Keywords}

PRECIS, Climate Extremes, Eastern Amazon, Mining, SPI

\section{Introduction}

In Brazil, the mining industry corresponds to an important share in the national economy, contributing approximately $4 \%$ to Brazil's gross domestic product (GDP) [1]. Due to the extension of its production chain, the mining industry builds up other economic sectors, contributes to the development of municipalities in its area of influence, and is responsible for generating jobs and tax revenue [2].

The mining industry chain is formed by logistical processes, beginning with mineral extraction and transportation using the railway system and ultimately reaching the port through which the production flows [3]. Most of these processes occur in the outdoors and are often impacted, directly or indirectly, by extreme weather events such as intense droughts and prolonged rainy periods, which interfere with operational routines, cause losses in production, and cause accidents with equipment and people. In studies in Canada regarding mineral vulnerability to climate variations, [4] found that mine areas showed significant climate risks.

Particularly in the eastern Amazon, between the southeastern area of Pará State and the western and northern parts of Maranhão State, mineral logistics processes occur at the Mineral Province of Carajás to the Ponta da Madeira Maritime Terminal, where mainly iron ore is exported [5]. This region, in turn, has a high spatial and temporal variability of rainfall [6] [7], where the greatest annual rainfall volumes are observed in the southern summer and fall seasons [8] [9].

Much of the rainfall variability in the eastern Amazon is modulated by large-scale circulation patterns due to the ocean-atmosphere interaction associated with surface temperatures of adjacent tropical oceans [10]. Possible anomalies in these temperatures cause significant changes in the circulation patterns, contributing to the occurrence of climate extremes, which may be associated with the ENSO (El Niño-Southern Oscillation) phases over the equatorial Pacific Ocean or with the southern interhemispheric temperature gradient of the sea surface in the tropical Atlantic Ocean [11]-[18].

Climate extremes have significant impacts on human activities, whether they occur in transportation, power generation, infrastructure, tourism, agriculture, or the mineral industry, among others [19]. While extreme rainfall events are 
characterized by intense and/or prolonged rainfalls, the dry climate extremes are marked by a series of consecutive days with no precipitation. Both cause different impacts, which are invariably associated with material damage to society or, in more severe cases, fatality victims.

In the Amazon, climate extremes have shown an increase in frequency in recent years [18] [20], with recurrent droughts in 2005 [21], 2010 [22] [23] and 2015 [24] and anomalous rainy periods in 2009 and 2012 [25] [26]. Some of these events caused historical minimums and maximums in Amazonian rivers and impacted the regional economy, which relies on the rivers for many activities.

To investigate future climate patterns, regional climate modeling allows a more detailed analysis of the regional characteristics, adjustments in physical parameters, parameterizations as well as predicting weather variables based on greenhouse gas (GHG) emission scenarios, aiming to assist the planning of decision makers in various sectors. By using dynamic downscaling, regional climate models allow an increase in the spatial resolution of the region and make more detailed descriptions possible for the topography, hydrography, soil cover, and continent-ocean boundaries, among other relevant characteristics, so that predictions are more accurate.

Studies such as [27] performed downscaling using the HadRM3P regional model contained in the Providing Regional Climates for Impact Studies (PRECIS) regional modeling system nested in the HadAM3P global model to analyze the distribution of temperature and rainfall extremes in South America in the current climate (1961-1990) and in the future climate (2071-2100); two scenarios (A2 and B2) of the AR4 (Fourth Assessment Report) of the Intergovernmental Panel on Climate Change (IPCC) were considered in the future climate analysis. In general, the results of the analyses showed that PRECIS simulated the distribution of extreme temperature and rainfall events well when compared to observations. Regarding future projections for the Amazon, the authors highlighted the increase in intensity of extreme rainfall events in most of the western part of the region and significant changes in the frequency of dry days in the eastern portion.

[28] performed dynamic downscaling with the REGCM4 regional model nested in the MPI global model for the current climate (1990-2012) and the near future climate (2015-2039) to study the characteristics of seasonal rainfall regimes and provide future climate scenarios in railway areas in the eastern Amazon and southeastern Brazil. Regarding future projections in the eastern Amazon railway areas, the results indicate a weak drop in rainfall along the railway during the rainy season (from January to May) and a sharp decrease in its northern (São Luís/MA) and southern (Carajás/PA) sections in the dry season (from June to October).

Given climate change scenarios and the problems related to the impact of adverse weather conditions on important economic activity in Brazil, this work 
aimed to provide an analysis on the impacts of climate extreme events in the mineral supply chain located in the eastern Amazon, using climate projections for the near future (2019-2050) considering intermediate scenario emission of greenhouse gases IPCC, RCP 4.5. Additionally, the performance of the regional modeling system (PRECIS) is evaluated by predicting the frequency of climate extremes during the current climate (1981 to 2005), as a contribution to regional scientific modeling studies in the Amazon.

\section{Data and Methodology}

\subsection{Study Area}

The study area (Figure 1(a)) is located east of the Amazon, between the Brazilian states of Pará (PA), Tocantins (TO) and Maranhão (MA). The North Corridor of Vale is a mineral logistics complex that connects ore extraction mines in southeastern Pará to the Ponta da Madeira Maritime Terminal, in São Luís/MA through the Carajás Railroad (EFC for its Portuguese acronym), which passes through 32 cities between these states.

The region is characterized by different elevations, reaching over $875 \mathrm{~m}$ (Figure 1(b)). In its southern portion, where the highest elevations of the region are observed, are the ore reserves of iron, manganese, copper, etc. The relief is also steep in the central portion, but it has no ore reserves. The lowest elevations are found in the northern portion of the EFC, in the municipality of São Luís, close to the average sea level.
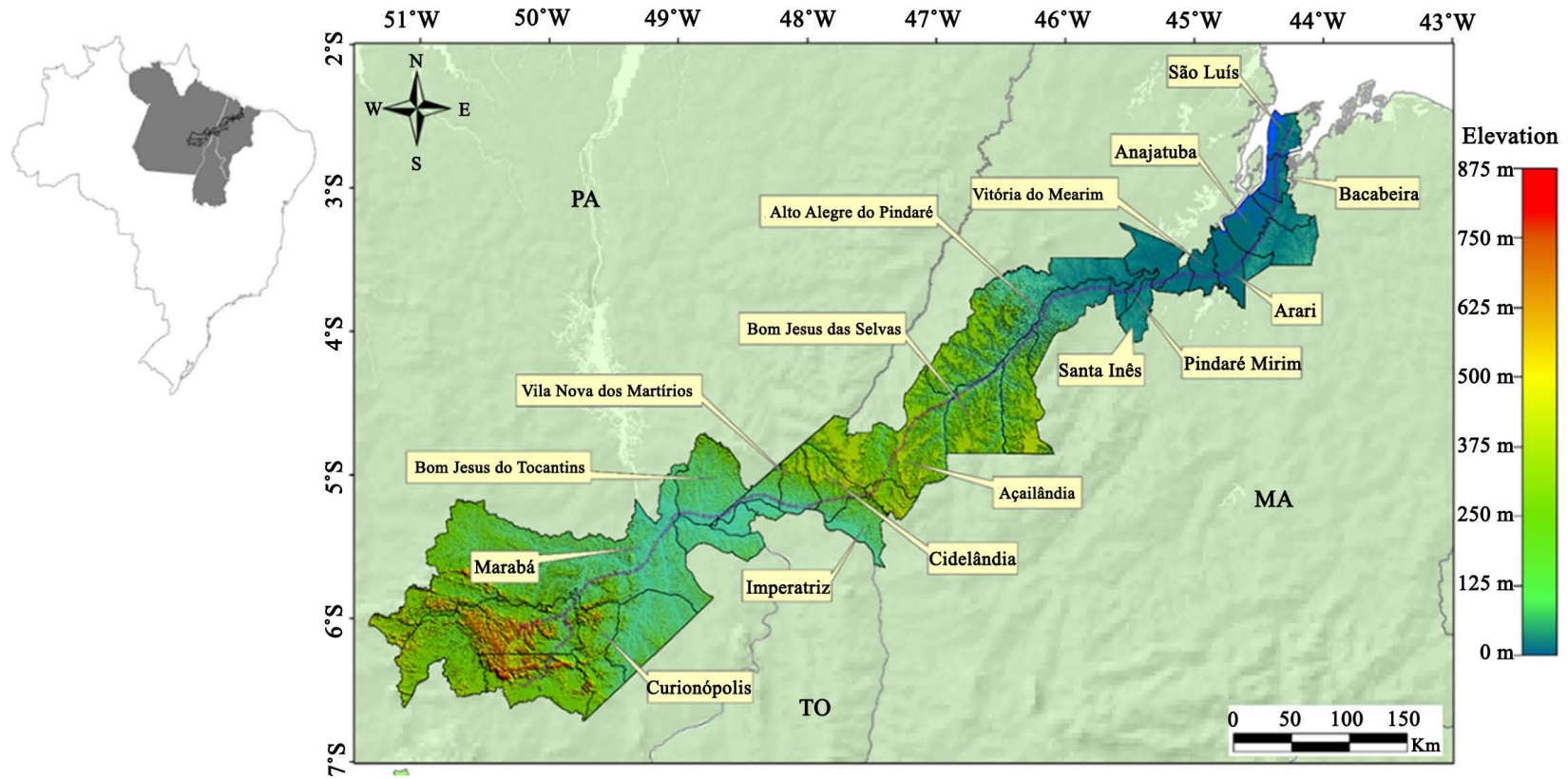

(a)

(b)

Figure 1. (a) Location of the study area in the eastern Amazon and (b) elevation map in meters (m) of the North Corridor of Vale. The black solid lines outline the municipalities through which the Carajás Railroad (EFC, purple line) passes in the states of Pará (PA), Tocantins (TO) and Maranhão (MA). Elevation data are from the SRTM (Shuttle Radar Topography Mission) DEM version 4 at $\sim 90$-m resolution, available at http://srtm.csi.cgiar.org/. 
Regarding the climate, this part of the Amazon is marked by spatial and temporal rainfall variability (Figure 2) associated with different atmospheric mechanisms in action [6] [7] [10] [29] [30] [31] among others. Observations (Figure 2) show that the rainy season begins along the North Corridor in the SON quarter (September-October-November) in the southern portion, with means between 100 and $175 \mathrm{~mm}$, in association with the formation of the South American Monsoon System [32] [33]. The southern summer, December-January-February (DJF), is marked by spatial rainfall variability, where high rainfall indices (above $275 \mathrm{~mm}$ ) are observed in the northwestern part of the region associated with the most central positioning of the band of clouds of the Intertropical Convergence Zone (ITCZ) [30] and in the southwestern portion of the region, over the mine areas; these indices can be explained by the South Atlantic Convergence Zone (SACZ) episodes, which are common during this quarter [34]. In MAM (March-April-May), which is the peak of the rainy season of the region, the highest rainfall indices (above $350 \mathrm{~mm}$ ) are observed throughout the northern portion, associated with the proximity of the ITCZ in combination with breeze circulation mechanisms that form the dynamic conditions of large and meso scales responsible for the formation of the Instability Lines [35], while the lowest rainfall volumes of the period are observed in the south-southeastern portion of the region, which may be due to the decrease in SACZ episodes and/or frontal systems [36]. Finally, the JJA quarter (June-July-August) is characterized by a significant decrease in

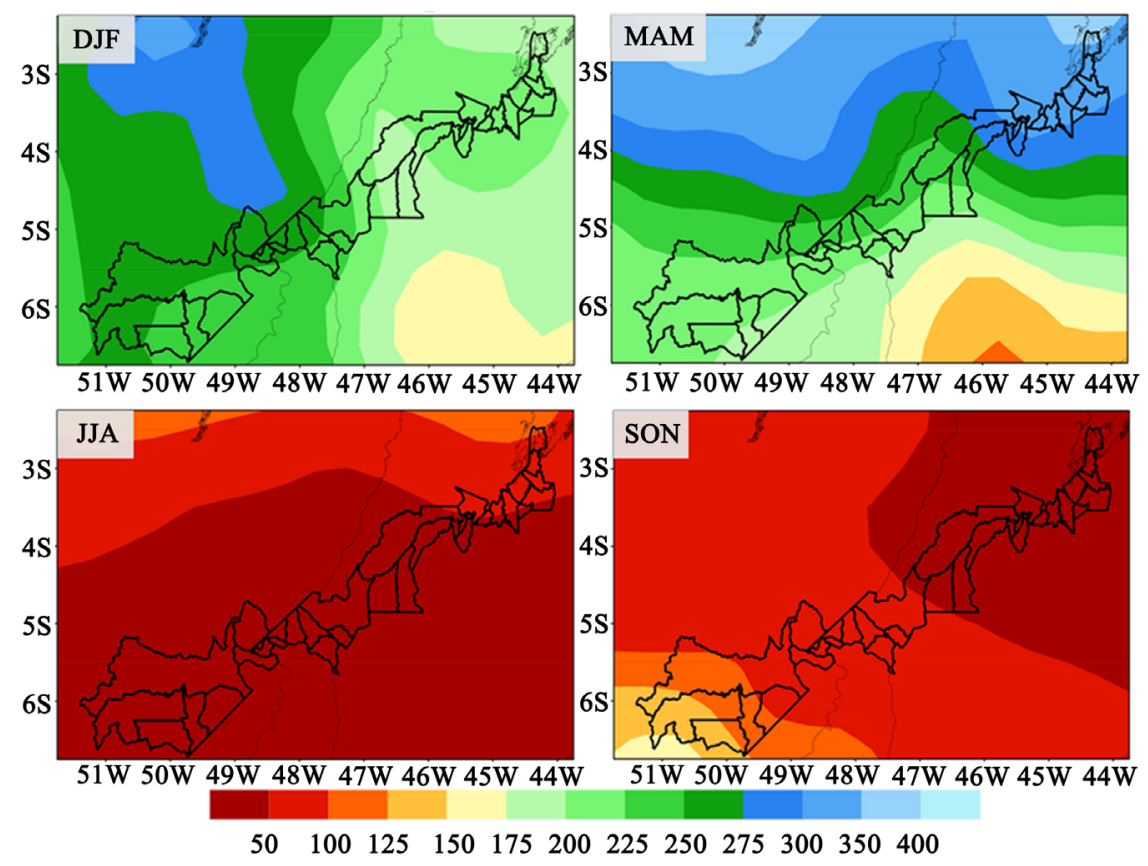

Figure 2. Spatial distribution of mean precipitation (25 years, 1981 to 2005) in the DJF (December-January-February), MAM (March-April-May), JJA (June-July-August) and SON (September-October-November) quarters with data from the CPC (Climate Prediction Center). The black lines outline the municipalities along the Carajás Railroad (EFC) in the states of Pará, Maranhão and Tocantins. The color scale indicates the intensity of rainfall $(\mathrm{mm})$. 
rainfall over the study area, establishing the drought season.

\subsection{Rainfall Data}

For this study, observed rainfall data and data simulated by regional climate modeling were used. The observation base is derived from daily rainfall data (mm) from the Climate Prediction Center (CPC) for 1981 to 2005. This dataset is based on rainfall records from surface weather stations distributed across the globe and arranged in a regular grid with a horizontal resolution of $0.5^{\circ}$ in terms of latitude and longitude [37].

The simulated precipitation consisted of daily data obtained from numerical integrations with the PRECIS climate modeling system, version 2.0 in a horizontal resolution of $0.22^{\circ}$ lat/lon $(\sim 25 \mathrm{~km})$. Details of the configuration of the experiments whose rainfall data were used in this work are described in the following subtopic.

For both datasets, observed and simulated, the monthly cumulative precipitation data were calculated from the daily data.

\subsection{Experimental Settings}

PRECIS is a numerical modeling system developed by the Met Office Hadley Centre and consists of a Regional Climate Model (RCM), HadRM3P, nested in a Global Circulation Model (GCM), which provides large-scale atmospheric and ocean conditions. The use of this technique, known as dynamic downscaling, allows a more realistic representation of the regional climate. The HadRM3P is coupled to the MOSES 2.2 (Met Office Surface Exchange) surface scheme, where surface temperatures, short and long wave radiation flows, sensible heat flows, soil heat flows, moisture content in the canopy, and snow melting rates are calculated for each surface type in a grid box [38]. More details on the characteristics of the regional model in PRECIS 2.0 can be seen in [39].

The global model HadGEM2-ES (Hadley Centre Global Environmental Model Version 2-Earth System) was used as contour conditions for the RCM, which is state-of-the-art for the Earth system, composed of a global circulation model of the atmosphere combined with an ocean model, and it also includes dynamic vegetation, biology of the ocean and atmosphere chemistry [40].

Integrations were performed with PRECIS for two climate periods: the first period representing the Current Climate or Historical scenario, integrated from December 1979 to November 2005, and the second period, representative of the Future Climate, from December 2005 to November 2050, for which the IPCC representative concentration pathway 4.5 (RCP 4.5) intermediate emission scenario was considered. However, the first year of integrations, called spin-up, was discarded. Spin-up is the time needed for the atmosphere and the Earth's surface to be adjusted to a state of mutual equilibrium [38]. Thus, for this work, the current climate was considered as the climate from 1981 to 2005 and the Future Climate was considered from 2019 to 2050.

The use of the IPCC RCP 4.5 scenario is justified because it is consistent with 
the Paris Agreement, a treaty in which countries that are part of the UNCC (United Nations Climate Change), including Brazil, direct their efforts to reduce greenhouse gas (GHG) emissions to limit an increase in the mean global temperature to $2^{\circ} \mathrm{C}$ or less. The RCPs are different concentration paths of GHG that may occur until the year 2100 and are incorporated into the numerical climate models [41].

The domain selected for integrations with the climate model covers much of South America and adjacent oceans (Figure 3), more precisely between $37.5^{\circ} \mathrm{S}$ and $13.25^{\circ} \mathrm{N}$ latitude (nx: 259 points) and between $90.25^{\circ} \mathrm{W}$ and $29^{\circ} \mathrm{W}$ longitude (ny: 236 points).

\subsection{Methodological Procedures}

\section{SPI Index and Climate Extreme Events}

The Standard Precipitation Index (SPI) was adopted to characterize extreme climate events in the precipitation data series, at each grid point over the study area. The use of SPI in this work was motivated by the simplicity of calculation and by its effectiveness in identifying dry and rainy events at different time scales, using only monthly precipitation data [42] [43] [44]. Therefore, it was initially necessary to adjust the monthly precipitation data series (observed and simulated) for a gamma distribution (Equation (1)), through a process of maximum likelihood estimation of the gamma distribution parameters, $\alpha$ and $\beta$. In simple terms, this process allows the distribution of precipitation in an area to be effectively represented by a mathematical cumulative probability function given by the expression:

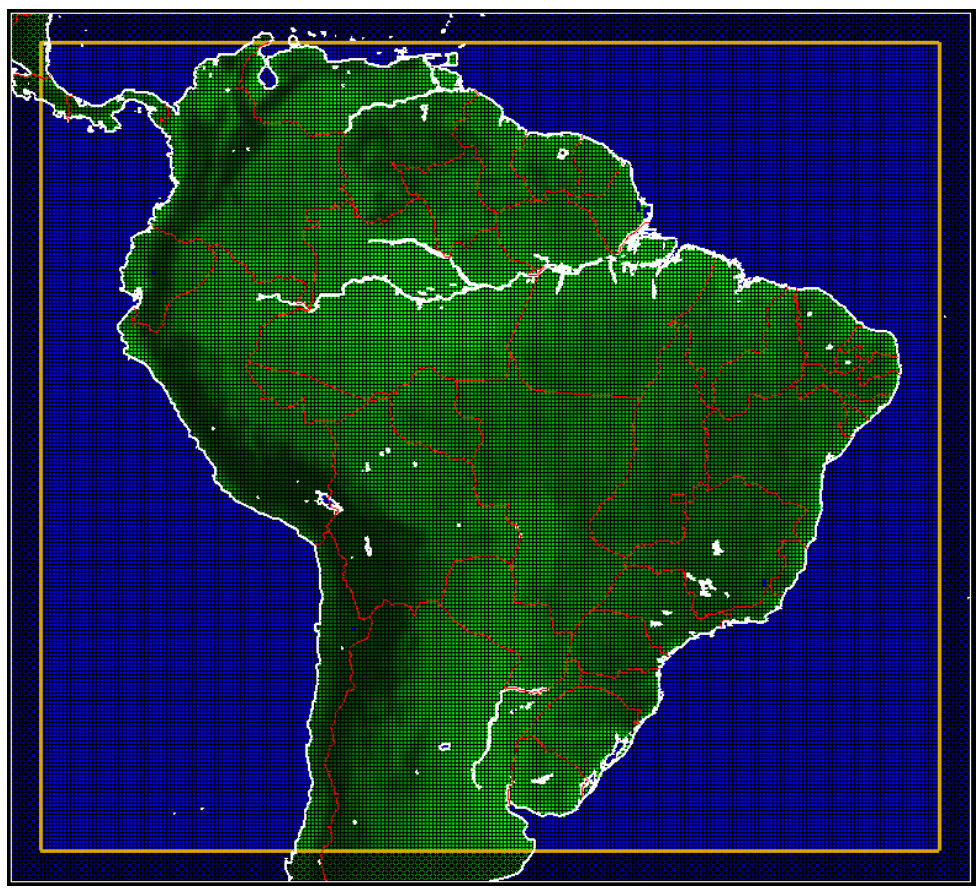

Figure 3. Domain of the integrations using the PRECIS model, covering parts of South America and adjacent oceans. 


$$
g(x)=\frac{X^{\alpha-1} \cdot \mathrm{e}^{-x / \beta}}{\beta^{\alpha} \Gamma(\alpha)} \text { for } X>0
$$

where $\alpha>0$ is the shape parameter; $\beta>0$ is the scale parameter; $X>0$ is the amount of precipitation in millimeters $(\mathrm{mm})$; and $\Gamma(\alpha)$ represents the complete gamma function.

Estimates of $\alpha$ and $\beta$ are given by Equations (2) and (3):

$$
\begin{gathered}
\alpha=\frac{1}{4 A}\left(1+\sqrt{1+\frac{4 A}{3}}\right) \\
\beta=\frac{\bar{x}}{\alpha}
\end{gathered}
$$

where $\bar{x}$ is the mean precipitation.

$$
A=\ln \bar{x}-\frac{\sum \ln x}{n}
$$

Given that $n$ is the number of observations, there is a normal probability distribution from the cumulative distribution. The cumulative probability of occurrence of each value is estimated and applied to the inverse normal function to find the SPI value, which represents the difference between the observed precipitation and the mean precipitation over a given time interval, divided by the standard deviation (Equation (5)).

$$
\mathrm{SPI}=Z_{i}=\frac{P_{i}-\bar{P}_{i}}{\sigma_{i}}
$$

where $P_{i}$ is the observed (simulated) precipitation and $\bar{P}_{i}$ and $\sigma_{i}$ are the mean precipitation and standard deviation of the adjusted series, respectively.

The SPI values were accounted, for each month, at each central grid point along the North Corridor (Figure 4). Thus, three datasets based on the SPI were obtained, where:

1) For the current climate: a dataset related to the CPC observations and another one related to the data simulated with PRECIS. For both datasets, the period considered was 1981 to 2005 and the horizontal resolution used was $0.5^{\circ}$ in latitude and longitude for a total of 43 grid points along the North Corridor (Figure 4(a));

2) For the future climate: a dataset for future simulation with PRECIS for 2019 to 2050 and resolution of $0.22^{\circ}$ in latitude and longitude for a total of 127 grid points along the North Corridor (Figure 4(b)).

Once the SPI has been determined for each month and at each central grid point of the North Corridor, the values were grouped by quarters: December-January-February (DJF), March-April-May (MAM), June-July-August (JJA) and September-October-November (SON), to analyze the seasonal variability of climate extremes.

In this study, the definition of extremes was based on the study by [42], where, for each time in data series, the quantitative values of SPI that exceed the absolute value of 1.5 are defined as climate extremes. Thus, the Rainy Extreme 


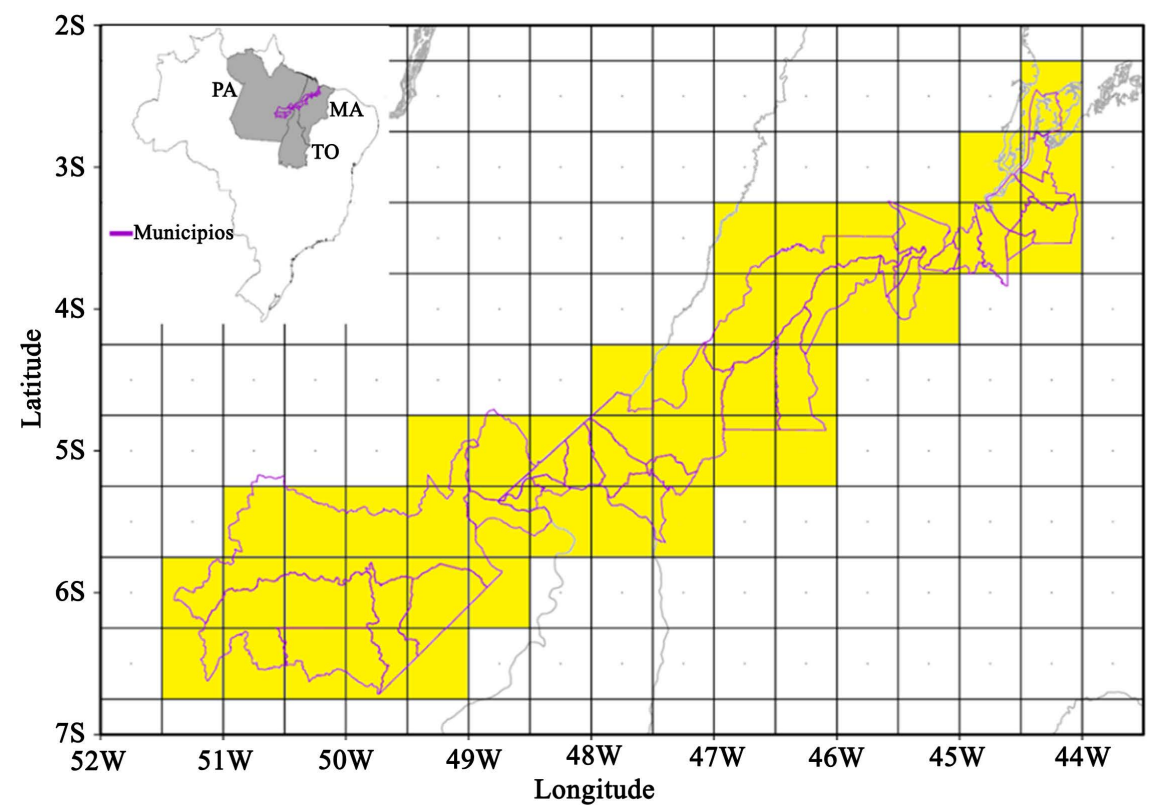

(a)

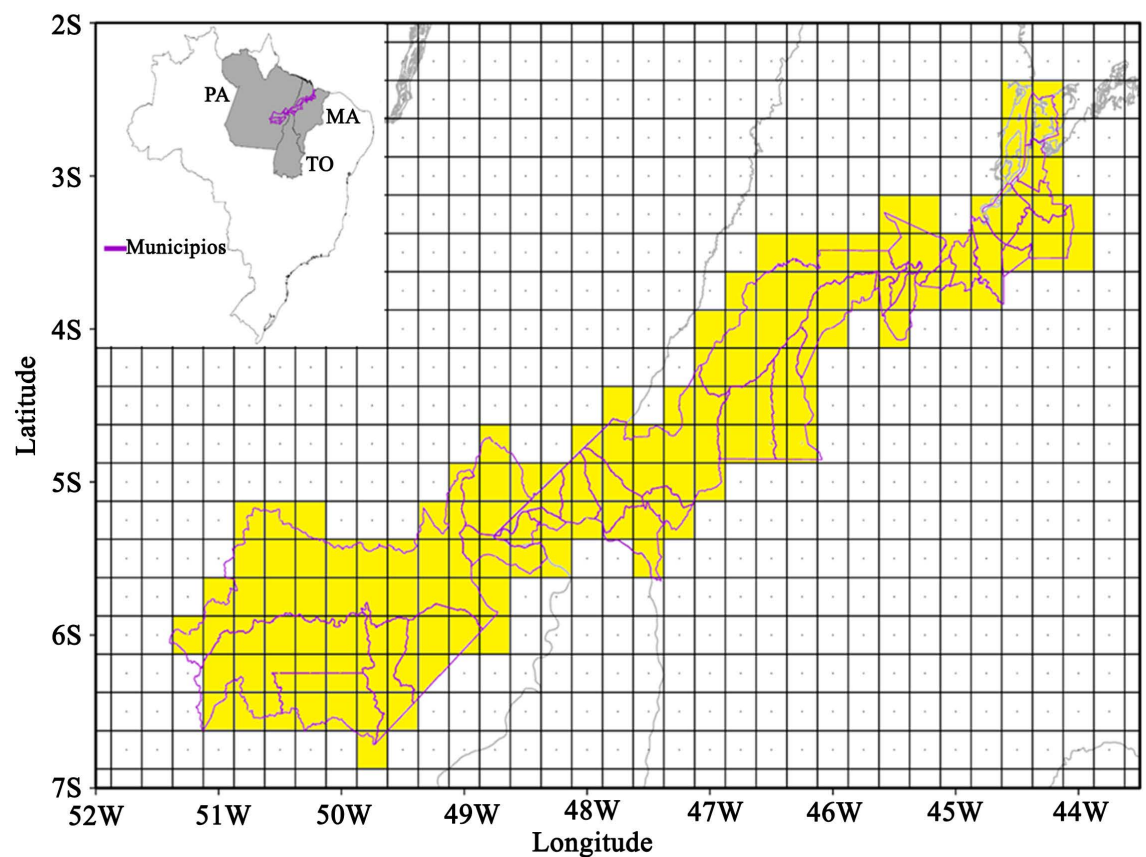

(b)

Figure 4. Grid points selected for the analysis of climate extremes along the mining chain in the eastern Amazon (in yellow) covering municipalities (purple contour) in the Brazilian states of Pará, Tocantins and Maranhão. In (a), each grid point has a resolution of $0.5^{\circ}$ in latitude/longitude for a total of 43 points, while in (b), the resolution is $0.22^{\circ}$ in latitude/longitude and 127 points in total.

(ExtRain) was categorized when the SPI value exceeds +1.5 , whereas the Extreme Dry (ExtDry) is defined when the SPI is less than -1.5 . Thus, the climate extremes are treated in terms of the standard deviation rather than the magnitude of precipitation. In the work of [42], these thresholds were classified as severe 
events and was also adopted by [43] and [45] in extreme studies for the eastern Amazon.

Finally, the relative frequencies $\left(F_{R}\right)$ of occurrences of Dry and Rainy Extremes were calculated throughout the SPI data series in each quarter, at each central grid point along the North Corridor, which is given by Equation (6):

$$
F_{R}=\left(\frac{F_{a}}{n}\right) \times 100
$$

where $F_{a}$ is the absolute frequency (number of times a given class or category os extremes appears in the data series, 25 years for the current climate (1981 to 2005 ) and 32 years for the future climate (2019 to 2050)) and $n$ is the number of sample elements.

\subsection{Bias}

A performance evaluation of the PRECIS model is also presented when simulating climate extremes from 1981 to 2005 in the study area, through the analysis of the bias. The bias method is provided by the difference between the $F_{R}$ values obtained from the outputs of the PRECIS model and the $F_{R}$ values obtained from the observed data according to Equation (7). Consequently, it was necessary to interpolate the original data of the model $\left(0.22^{\circ} \times 0.22^{\circ}\right.$ latitude and longitude $)$ for the same horizontal resolution of the observed data $\left(0.50^{\circ} \times 0.50^{\circ}\right.$ latitude and longitude) using the bilinear interpolation of the free software CDO (Climate Data Operators). More information on CDO is provided at https://code.mpimet.mpg.de/projects/cdo/.

$$
V_{F_{R}}=F_{R} M-F_{R} O
$$

where $F_{R} M$ is the relative frequency of the SPI based on the model data and $F_{R} O$ is the frequency obtained from the observed data (CPC).

\section{Results and Discussion}

The evaluation of the regional model PRECIS in reproducing the climate extremes along the mining chain region in the eastern Amazon region, hereinafter called the mineral chain, is based on the comparison with the observational network of the CPC from 1981 to 2005. The probabilities of occurrences of these extremes in the future (up to 2050) are obtained from the simulations with PRECIS, considering the IPCC RCP 4.5 intermediate emission scenario. The analyses were performed by quarters of the year (DJF, MAM, JJA and SON), and the results are presented in maps.

\subsection{Skill Analysis of the Climate Regional Model}

It is essential to evaluate the performance of the climate model, since systematic errors of the regional climate model, as well as those inherited by the global model that served as a boundary condition for the downscaling, in reproducing the current climate, should be considered in the analysis of future projections for the region. Figure 5 and Figure 6 show, respectively, the bias of relative 


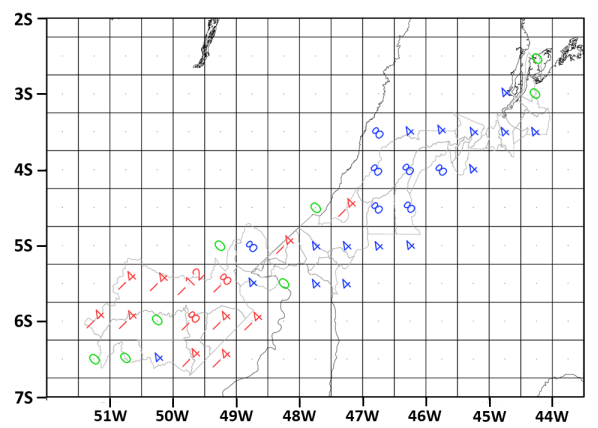

(a)

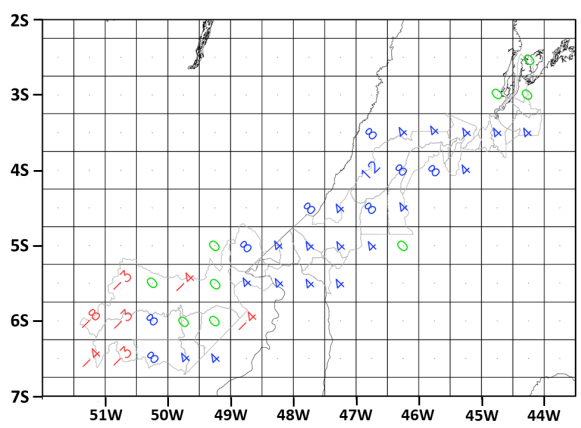

(b)

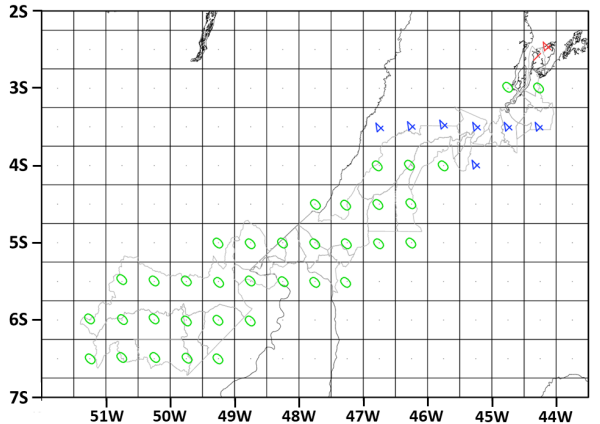

(c)

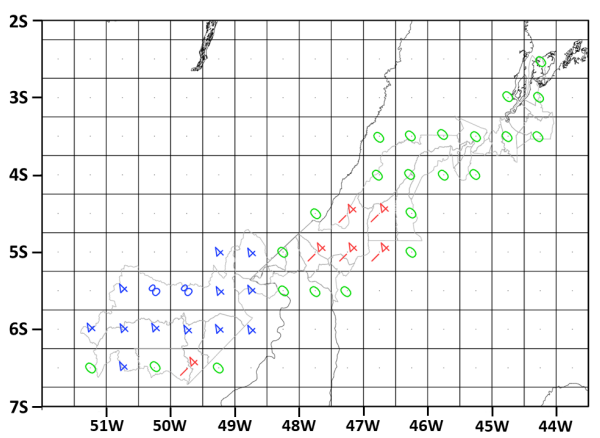

(d)

Figure 5. Relative frequency bias of Dry Extremes (ExtDry) in the quarters of (a) December to February (DJF); (b) March to April (MAM); (c) June to August (JJA) and (d) September to November (SON). The numbers refer to the bias magnitude, where the positive numbers (in blue) indicate that the model overestimates the observed ones, while the negative numbers (in red) indicate that the model underestimates them. The zero (in green) denotes that the model was in accordance with what was observed. Unit: in percentage (\%). 
frequencies of dry and rainy climate extremes in the current climate (1981 to 2005) along the mineral chain. In these figures, positive values (in blue) indicate that PRECIS overestimated the frequency of extremes compared to what was observed, while negative values indicate that the model underestimated (in red) their occurrences. The grid points containing the number zero highlighted in green indicate that the model showed good accuracy when simulating climate extremes.

For the category of dry climate extremes (Figure 5), there is great spatial variability of bias throughout the study area in the southern summer (DJF, Figure $5(\mathrm{a})$ ), where, in most of its southern (central) portion, the regional model underestimated (overestimated) this category of extremes; however, in the squares located further north, the model shows good accuracy. The MAM quarter (Figure 5(b)) also showed high spatial variability of bias, but positive values predominated, mainly in its central portion. However, the good accuracy of PRECIS in representing the dry extremes on the squares located further north is noteworthy. In the southern winter (JJA, Figure 5(c)), when rainfall is reduced in the region, the model reproduces the frequency of dry extremes along the studied area well except in the squares located further north. From September to November (SON, Figure 5(d)), in general, the model is more accurate when it represents the frequencies of dry extremes in the north-central portion of the study area; however, it overestimates them in the southern portion.

Regarding the frequency of rainy extremes on the mineral chain (Figure 6), despite the high spatial variability of bias in DJF (Figure 6(a)), positive values (overestimate) predominate in the southern portion, and negative values (underestimate) predominate in the north-central portion. In the MAM quarter (Figure 6(b)), negative bias values prevail, mainly in the southern portion of the study area. In addition, it is valid to comment on the negative bias on the northern portion, where the highest annual rainfall indices are recorded during this period. In the JJA quarter (Figure 6(c)), in general, the model overestimates the occurrence of rainy events in the southern portion of the study area, but it represents this category well in the northern portion. In the SON quarter (Figure 6(d)), which is representative of the beginning of the rainy season in the southern portion of the study area, the model underestimates the rainy extremes in the mineral extraction region but it shows a good performance in much of the north-central portion of the study area, with emphasis on the grid points closest to the São Luís port region (MA).

In general, the model overestimates the ExtDry and underestimates the ExtRain in the rainy season (DJF and MAM). According to [46], the PRECIS, nested in HadGEM2-ES, underestimates precipitation in the north of the eastern Amazon between the months of December and May, and is associated with the difficulty of the regional model in adequately capturing of the Intertropical Convergence Zone (ITCZ) in the region. Another general point worth mentioning is the underestimation of the rainy extremes in the southern portion of the 


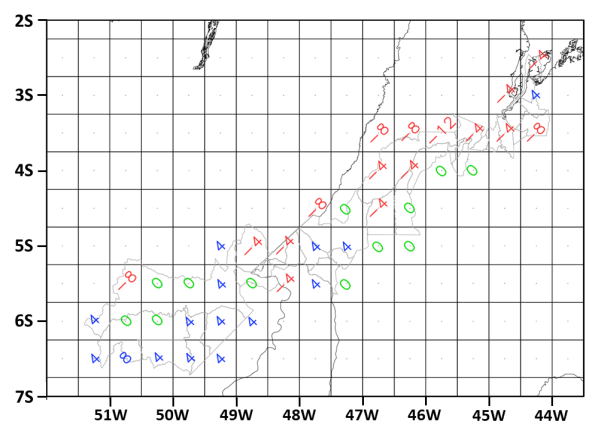

(a)

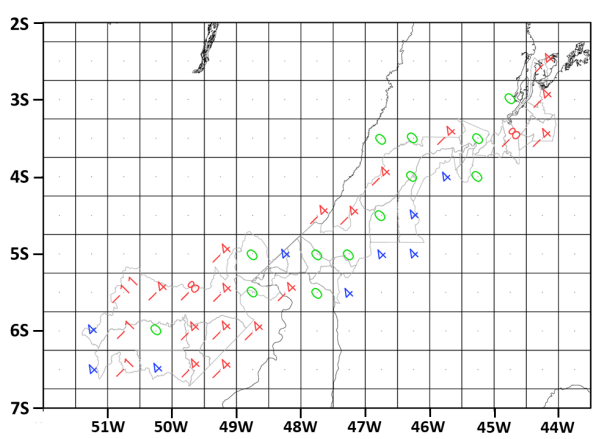

(b)

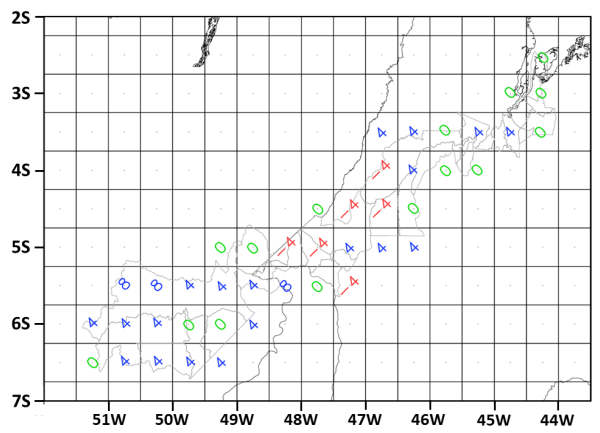

(c)

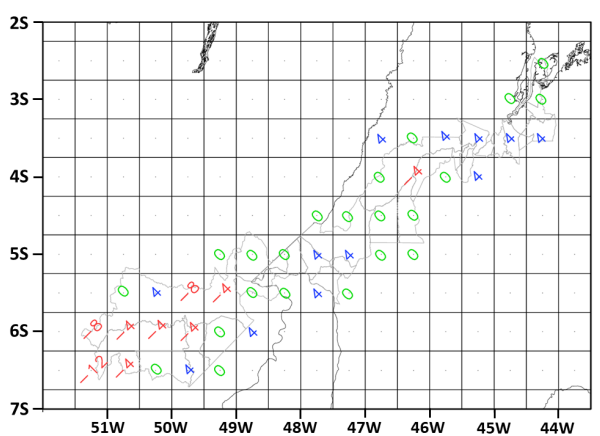

(d)

Figure 6. Relative frequency bias of rainy extremes (ExtRain) in the quarters of (a) December to February (DJF); (b) March to April (MAM); (c) June to August (JJA) and (d) September to November (SON). The numbers refer to the bias magnitude, where the positive numbers (in blue) indicate that the model overestimates the observed ones, while the negative numbers (in red) indicate that the model underestimates them. The zero (in green) denotes that the model was in accordance with what was observed. Unit: in percentage (\%). 
study area in the MAM and SON quarters. Because they are the transition seasons between dry and rainy regimes and vice versa, the model has difficulties in representing this category of events. According to [27] [47], this difficulty may be associated with the inadequate parameterization of radiation or surface processes and effects of the local dynamic forces, such as wet or dry soil, which ultimately predominate over large-scale forcings. This proposition can be further supported with a characteristic of the short SPI (1 - 3 months) related to the response of regional soil moisture conditions in relation to rainfall in short range (44). Furthermore, the HadGEM2-ES global model, which provided the contour conditions for the experiment, does not have the same formulation as the regional model within PRECIS (HadRM3P). Thus, systematic errors of the global model may be inherited by HadRM3P [47].

The great bias variability of climate extremes on the study area may also be related to the low density of weather stations in the eastern Amazon, which are interpolated to obtain CPC data, thus compromising the performance evaluation of the model on the regional climate, as indicated in the study by [27]. Another very important factor that may also be influencing these estimation errors, mainly related to estimation of precipitation and implying a great variability of the bias, is the poor representation of the surface coverage in the region given by the surface scheme coupled with the regional model, given that any change in surface coverage can impact the frequency of precipitation extremes [48].

\subsection{Climate Extremes Probability}

This section presents the results of the probability of occurrence of dry (ExtDry) and rainy (ExtRain) climate extremes between 2019 and 2050 for the mineral chain region. Climate extremes were approached considering seasonality and were analyzed separately since anomalous dry and rainy events generate different impacts.

Thus, Figure 7 shows the ExtDry probability results, considering the DJF (Figure 7(a)), MAM (Figure 7(b)), JJA (Figure 7(c)), and SON (Figure 7(d)) quarters. The percentage scale of the probability of extremes shows a color gradient (shades of yellow to red) associated with values between $0 \%$ and $12.5 \%$. The DJF and MAM quarters, characterized by the highest regional rainfall volume, have the highest percentage values of ExtDry probability, shown by the number of orange and red squares. These squares are distributed throughout the study region. However, the highest percentages are located in the north-central portion, as shown in Figure 7(a) and Figure 7(b). Moreover, the JJA and SON quarters showed contrasting percentage values in the study area. In Figure 7(c), representing the JJA quarter, there is a higher percentage of probability of ExtDry in the north-central portion of the region, predominantly in the squares located in the state of Maranhão. However, the percentages are not as high as those observed in the DJF and MAM quarters. In the southern portion of the region, the percentages of probability of ExtDry are close to zero since it is not possible to classify ExtDry in regions where, historically, precipitation totals are 


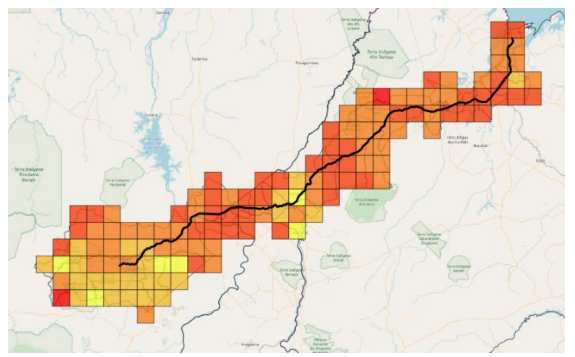

(a)

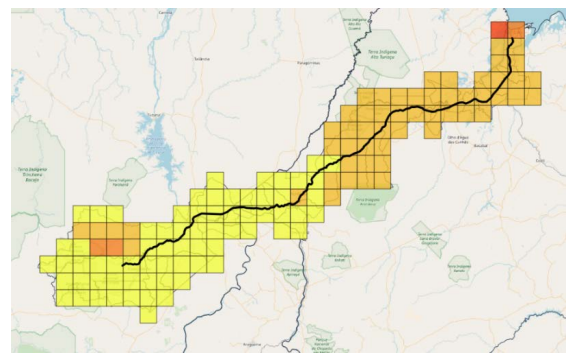

(c)

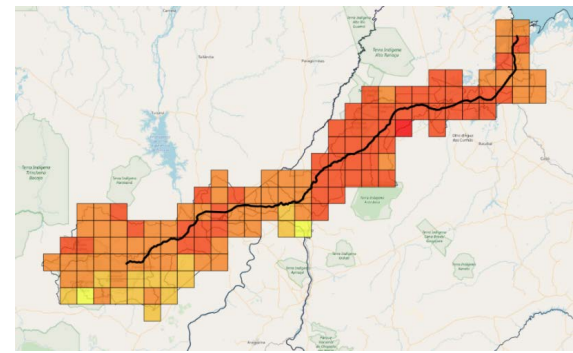

(b)

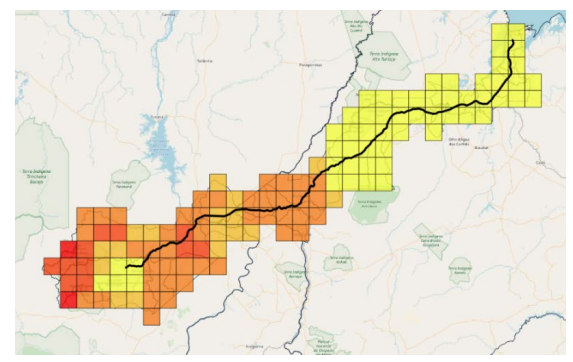

(d)

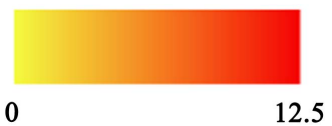

Figure 7. Probability of extreme dry events for the next 32 years (2019 to 2050) in the quarters of (a) December to February; (b) March to May; (c) June to August and (d) September to November. The fine and thick black lines respectively represent the outlines of the Brazilian States and the Carajás Railroad (EFC), which connects the mining complex to the maritime port. The color scale indicates the relative frequency of weather events along the North Corridor. Unit: Percent (\%).

low, as in the case of the JJA quarter [8] [49]. Unlike what was observed in the immediately preceding quarter, in the SON quarter it is possible to observe the highest percentage values of the probability of ExtDry in the squares of the southern portion of the region up to the border between the states of Pará, Tocantins, and Maranhão, while in the north-central portion, the percentages are close to zero due to low precipitation volumes.

The ExtRain probability maps in the mineral chain (Figure 8) show different seasonal characteristics, with probability percentage values ranging from 0 to $18.8 \%$ (shades from green to purple). The DJF quarter is shown in Figure 8(a), where it is possible to observe the intermediate portion and the squares near the port region with the highest percentages of ExtRain probability. Figure 8(b), representing the MAM quarter, shows a higher probability of ExtRain in the southern portion, near the beginning of the mineral chain, a higher probability of ExtRain, while the percentage values are close to zero for the other squares. The JJA period is the one with the lowest probability of ExtRain in the entire region. This condition is evidenced by the green squares distributed along the study area (Figure $8(\mathrm{c})$ ). The SON quarter, shown in Figure $8(\mathrm{~d})$, presents the highest percentage of ExtRain values in the north-central portion of the region, especially in the squares closest to the end of the mineral chain where the port 


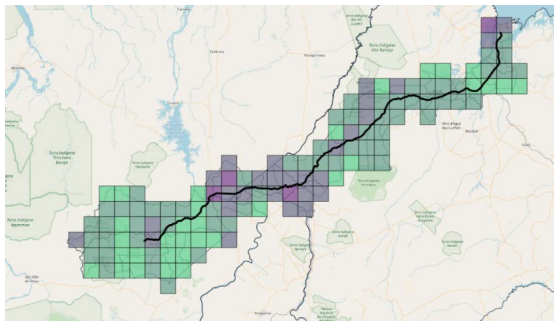

(a)

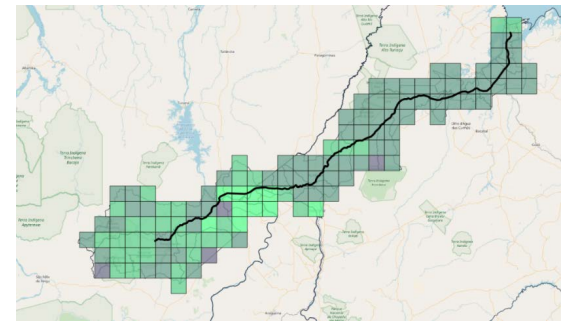

(c)

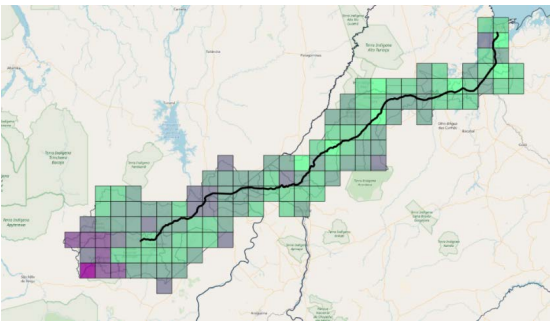

(b)

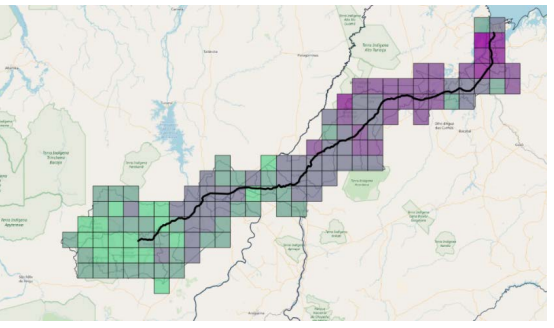

(d)

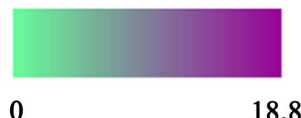

Figure 8. Probability of extreme rainy events for the next 32 years (2019 to 2050) in the quarters of (a) December to February; (b) March to May; (c) June to August and (d) September to November. The fine and thick black lines respectively represent the outlines of the Brazilian States and the Carajás Railroad (EFC), which connects the mining complex to the maritime port. The color scale indicates the relative frequency of weather events along the North Corridor. Unit: Percent (\%).

region is located, whose percentages are close to the maximum values of the color scale. The ore extraction region has a low percentage of ExtRain probability in the SON quarter as well as in the DJF and JJA quarters.

The mapping results of the probability of occurrence of ExtDry and ExtRain between 2019 and 2050 showed peculiarities between periods and regions with lower and higher percentages. In general, the results showed a higher probability of ExtRain throughout the region, confirmed by the highest percentage values compared to ExtDry.

During the rainy season, water drainage in the product storage yards is an obstacle to the flow of operation in the mineral chain. However, the projections of the climate model show an increase in the frequency of ExtRain in the region, which may further aggravate the problems with drainage. In addition, it may also favor the occurrence of natural disasters in the region, such as flooded rivers and the collapse of embankments, since the soil is already saturated.

For both analyses of the climate extremes, the JJA, period where the lowest rainfall in the year in the study region is recorded, quarter showed lower probability percentages, characterizing the period as the most appropriate for optimizing mineral production, transportation on the railroad and ore loading on ships, which should be conducted with little or no precipitation. However, the MAM quarter for the Carajás region and the SON quarter for the area north of 
the railway correspond to the less desirable periods for mining activities, given the higher probability of ExtRain. Climatologically, the SON quarter marks the beginning of the rainy season in the southern part of the region, where the extraction mines are located. However, future projections of extremes indicate a higher percentage of ExtSc in the central-south portion for the SON quarter, while for the central-north portion, where part of the railway and port is located, a higher frequency of ExtRain is predicted. This may indicate possible delay or anticipation of the beginning of the rainy season in the central-southern and central-northern portions of the region, respectively, for some years.

Although the excess of rainfall is a problem for mining, a prolonged period with no precipitation is also considered a hindrance, more precisely in extraction activities that use water in the mining processes and ore processing. In this sense, the DJF, MAM and SON quarters showed the highest probability percentages of ExtDry between 2019 and 2050, indicating a higher frequency of periods without precipitation. In a scenario of prolonged drought, associated with an increase in the frequency of ExtSc, it can compromise the replacement of water in the soil for the following periods, impairing the demands of human activities and the environment. Another aggravating scenario is related to the high frequency projections of ExtSc in the dry season, which can intensify the environmental conditions conducive to the occurrence of forest fires due to the low humidity and high temperatures, which can reduce the speed of ore transport by rail, once the visibility of the train operator is reduced due to smoke, or even its total stop until conditions improve. In addition, these fires result in loss of biodiversity in the region, contribute to $\mathrm{CO}_{2}$ emissions into the atmosphere and also reduce air quality in the vicinity of the event.

Most of the mineral chain processes occur in the outdoors, such as equipment and railroad maintenance. In the Amazon, in general, extreme precipitation events associated with convective meteorological systems are accompanied by lightning strikes. As future projections indicate a higher percentage of extreme rainy events over the study region, an increase in the number of lightning strikes is expected, mainly in the central-northern portion of SON. In view of this hypothesis, it is valid to recommend to decision makers that they consider this information in their long-term planning, and that they also constantly monitor weather and climate conditions to mitigate risks and ensure the health and safety of their employees. When comparing the results of this study with those found in the literature, it was found that most studies are associated with climate change in large regions and do not address the impacts on industries, such as the mineral chain in the eastern Amazon. The studies emphasize the increase in temperature and the variation of precipitation relative to the current climate. However, there are studies on the frequency of climate extremes with different approaches, such as [43], who evaluated the frequency of extreme drought and rain events in the Amazon using four databases from 1979 to 2014 (36 years). The authors also used the SPI methodology to define dry and rainy extremes, applied over different time scales (3, 6 and 12 months), and found different re- 
sults from those in the present study, whose frequency of ExtRain from 2019 to 2050 was higher in percentage compared to ExtDry. [43] found that in the three SPI time scales, in all seasons of the year, and in the four databases, the Amazon showed frequencies of extreme rain events ranging from $3 \%$ to $6 \%$ in the study period. However, they observed that extreme drought events showed a variation of more than $6 \%$ of the frequencies. In addition to the results of these authors, the present study showed ExtRain and ExtDry increase projections for the period of 2019 to 2050 (32 years) in the eastern Amazon, which is a region of important economic activity for Brazil, the mining industry, which occurs outdoors and is significantly affected by weather events.

The study by [50], evaluated the changes in daily extremes of temperature and precipitation throughout the planet based on a set of climate change indices for the period from 1901 to 2003 and revealed that they occur in all seasons of the year, although they are less pronounced during the months from September to November. They also showed a trend of increasing rainy weather extremes throughout the 20th century. In the present study, the southern spring quarter showed high percentage values of probability of climate extremes, both dry and rainy. For the eastern Amazon, this period represents the beginning of the rainy season in much of the mineral chain, and the results indicate possible changes in regional rainfall patterns.

Since the climate in the Amazon is modulated by large-scale circulation patterns, associated with surface conditions in the adjacent tropical oceans, a large part of the rainfall variability in the region is defined by such effects through the interaction between ocean-atmosphere [10]. As a striking feature of the climate in the region, rainfall presents with high spatial and temporal variability, which sometimes become extreme rainy or dry. In this context, the forecast of climate extremes for up to 2050 in eastern Amazonia can be associated with anomalies in the sea surface temperature of the adjacent oceans, specifically the hot and cold phases of the El Niño-Southern Oscillation (ENSO) in the Tropical Pacific Ocean [11] [12] [14] [17] and/or interhemispheric gradient in the Tropical Atlantic [8] [13] [16] [18]. Not least, these events can also be related to regional circulation due to changes in land cover, which was not the object of study in this work.

\section{Conclusions and Recommendations}

Considering projections for the near future (2019 to 2050) in the context of climate change, this work analyzed the seasonal patterns of climate extremes in eastern Amazonia, exploring their impacts on the mineral production chain, which goes from the mineral extraction mine to the port. Future projections were obtained from simulations with the regional modeling system PRECIS nested to the global model HadGEM2-ES, considering the intermediate scenario of global warming of the IPCC. The dry and rainy climate extremes were defined using the SPI (Standard Precipitation Index), initially applied to the monthly precipitation data series and later grouped into quarters. The analyses were 
based on the relative frequency of the categories of dry and rainy extremes. Additionally, the performance of the modeling system in identifying the climate extremes in the present climate (1981 to 2005) was evaluated by comparing it with observed data from the Climate Prediction Center (CPC).

As main highlights on the evaluation of the regional model determined by the bias of the relative frequency of extremes:

- The high spatial bias variability of relative frequencies of extremes over the study area indicates that the model is more accurate when detecting dry seasonal climate extremes than the other category of extremes;

- Particularly in the center-south portion of the region (mines and part of the railway), for both categories of climate extremes, PRECIS showed better accuracy in the JJA quarter when compared to the others;

- In general, along the mineral chain in eastern Amazonia, the regional model performs better over the port region, by representing dry climate extremes, except in JJA, and rainy climate extremes, except in the rainy season (DJF and MAM). Previous studies, which assessed PRECIS 'ability to represent seasonal precipitation in eastern Amazonia, indicated the model's low accuracy in reproducing the Intertropical Convergence Zone, the main meteorological system that causes rainfall in the region at this period.

Regarding the probabilities of extremes in the future:

- There is a higher probability of rainy extremes throughout the region from 2019 to 2050, with an associated possible increase in lightning strikes, mainly in the central-northern portion in the SON quarter;

- There is less likelihood of extremes in the JJA quarter; thus, it is the most appropriate period for the mineral chain to optimize its production, transportation on the railroad and the loading of ores on ships;

- The MAM quarter in the mining region in Carajás/PA and the SON quarter in the area north of the railway, correspond to the less desirable periods for mining activities due to the higher probability of rainy climate extremes.

The present work brings a pioneering scientific approach in predicting the occurrence of extreme events for eastern Amazonia considering the 2050 horizon and an advance in studies on the impact of precipitation along the mining chain. Although the present study uses only a regional climate model to investigate the probability of climate extremes, the results of the study show scientific solidity.

The results of this study suggest an increasing risk to the processes of the mineral chain until 2050 associated with the occurrence of climate extremes, since it is susceptible to adverse weather and climate conditions. However, the analyzes provided by this study can help decision makers and stakeholders to carry out long-term planning considering the impacts of climate extremes in the future on the processes in the mineral chain.

Finally, in order to minimize the limitations of the methodology used in this study, it is suggested for future works, consider using multi-model ensembles 
and additional data sources observed for evaluation of regional modeling. It is also important to consider the change in land cover, since the regional surface characteristics are also a key factor for the occurrence of climate extremes.

\section{Acknowledgements}

This study was supported in part by the Coordenação de Aperfeiçoamento de Pessoal de Nível Superior-Brasil (CAPES)—Finance Code 001. We would like to thank Dr. Lincoln Alves (CCST/INPE) for providing the data for the models used in this work, as well as his intermediation with the Met Office Hadley Centre (England), the developer of the models, and Dr. Cecílio Fróis (ITVDS) for assisting with the calculation of the SPI. The first author would like to thank Yoko Ishida and Andrew Gray-Spence for their support in revising English grammar.

\section{Conflicts of Interest}

The authors declare no conflicts of interest regarding the publication of this paper.

\section{References}

[1] Departamento Nacional de Produção Mineral (DNPM). Sumário Mineral 2015. Brasília. http://www.dnpm.gov.br/dnpm/sumarios/sumario-mineral-2015

[2] Instituto Brasileiro de Mineração (2016) Gestão e Manejo de Rejeitos da Mineração. Instituto Brasileiro de Mineração, Brasília, 128 p.

[3] Katz, F. (2014) Recursos Minerais e a Economia do Conhecimento. In: de Mello Belluzzo, L.G., Frischtak, C.R. and Laplane, M., Eds., Produção de Commodities e Desenvolvimento Econômico, UNICAMP, Instituto de Economia, Campinas, 126 p.

[4] Pearce, T.D., et al. (2011) Climate Change and Mining in Canada. Mitigation and Adaptation Strategies for Global Change, 16, 347-368. https://doi.org/10.1007/s11027-010-9269-3

[5] Vale: Relatório de Sustentabilidade (2016). http://www.vale.com/PT/investors/information-market/annual-reports/sustainabilit yreports

[6] Salati, E., et al. (1979) Recycling of Water in the Amazon Basin: An Isotopic Study. Water Resources Research, 15, 1250-1258. https://doi.org/10.1029/WR015i005p01250

[7] Figueroa, S.N. and Nobre, C.A. (1990) Precipitation Distribution over Central and Western Tropical South America. Climanálise, 6, 36-40.

[8] Silva Ferreira, D.B.S., et al. (2015) Spatial and Temporal Variability of Rainfall in Eastern Amazon during the Rainy Season. The Scientific World Journal, 2015, Article ID: 209783. https://doi.org/10.1155/2015/209783

[9] Marengo, J.A., et al. (2001) Onset and End of the Rainy Season in the Brazilian Amazon Basin. Journal of Climate, 14, 833-852. https://doi.org/10.1175/1520-0442(2001)014<0833:OAEOTR >2.0.CO;2

[10] Liebmann, B. and Marengo, J. (2001) Interannual Variability of the Rainy Season and Rainfall in the Brazilian Amazon Basin. Journal of Climate, 14, 4308-4318. https://doi.org/10.1175/1520-0442(2001)014<4308:IVOTRS >2.0.CO;2 
[11] Kousky, V.E., et al. (1984) A Review of the Southern Oscillation: Oceanic-Atmospheric Circulation Changes and Related Rainfall Anomalies. Tellus A, 36, 490-504. https://doi.org/10.1111/j.1600-0870.1984.tb00264.x

[12] De Souza, E.B., et al. (2000) On the Influences of the El Niño, La Niña and Atlantic Dipole Pattern on the Amazonian Rainfall during 1960-1998. Acta Amazônica, 30, 305-318. https://doi.org/10.1590/1809-43922000302318

[13] Ronchail, J., Cochonneau, G., Molinier, M., Guyot, J.L., Chaves, A.G.D.M., Guimaraes, V. and Oliveira, E. (2002) Interannual Rainfall Variability in the Amazon Basin and Sea-Surface Temperatures in the Equatorial Pacific and the Tropical Atlantic Oceans. International Journal of Climatology, 22, 1663-1686.

https://doi.org/10.1002/joc.815

[14] Coelho, C.A.S., et al. (2002) Exploring the Impacts of the Tropical Pacific SST on the Precipitation Patterns over South America during ENSO Periods. Theoretical and Applied Climatology, 71, 185-197. https://doi.org/10.1007/s007040200004

[15] Yoon, J.H. and Zeng, N. (2010) An Atlantic Influence on Amazon Rainfall. Climate Dynamics, 34, 249-264. https://doi.org/10.1007/s00382-009-0551-6

[16] Andreoli, R.V., et al. (2011) Seasonal Anomalous Rainfall in the Central and Eastern Amazon and Associated Anomalous Oceanic and Atmospheric Patterns. International Journal of Climatology, 32, 1193-1205. https://doi.org/10.1002/joc.2345

[17] Marengo, J.A., Alves, L.M., Soares, W.R., Rodriguez, D.A., Camargo, H., Riveros, M.P. and Pabló, A.D. (2013) Two Contrasting Severe Seasonal Extremes in Tropical South America in 2012: Flood in Amazonia and Drought in Northeast Brazil. Journal of Climate, 26, 9137-9154. https://doi.org/10.1175/JCLI-D-12-00642.1

[18] Satyamurty, P., da Costa, C.P.W., Manzi, A.O. and Candido, L.A. (2013) A Quick Look at the 2012 Record Flood in the Amazon Basin. Geophysical Research Letters, 40, 1396-1401. https://doi.org/10.1002/grl.50245

[19] Handmer, J., et al. (2012) Changes in Impacts of Climate Extremes: Human Systems and Ecosystems. In: Field, C.B., Barros, V., Stocker, T.F., Qin, D., Dokken, D.J., Ebi, K.L., Mastrandrea, M.D., Mach, K.J., Plattner, G.-K., Allen, S.K., Tignor, M. and Midgley, P.M., Eds., Managing the Risks of Extreme Events and Disasters to Advance Climate Change Adaptation, A Special Report of Working Groups I and II of the Intergovernmental Panel on Climate Change (IPCC), Cambridge University Press, Cambridge, New York, 231-290. https://doi.org/10.1017/CBO9781139177245.007

[20] Marengo, J.A. and Espinoza, J.C. (2016) Extreme Seasonal Droughts and Floods in Amazonia: Causes, Trends and Impacts. International Journal of Climatology, 36, 1033-1055. https://doi.org/10.1002/joc.4420

[21] Marengo, J.A., et al. (2008) The Drought of Amazonia in 2005. Journal of Climate, 21, 495-516. https://doi.org/10.1175/2007JCLI1600.1

[22] Lewis, S.L., Brando, P.M., Phillips, O.L., van der Heijden, G.M. and Nepstad, D. (2011) The 2010 Amazon Drought. Science, 331, 554. https://doi.org/10.1126/science.1200807

[23] Marengo, J.A., Tomasella, J., Alves, L.M., Soares, W.R. and Rodriguez, D.A. (2011) The Drought of 2010 in the Context of Historical Droughts in the Amazon Region. Geophysical Research Letters, 38, 1-5. https://doi.org/10.1029/2011GL047436

[24] Jiménez-Muñoz, J.C., et al. (2016) Record-breaking warming and extreme drought in the Amazon rainforest during the course of El Niño 2015-2016. Scientific Reports, 6, Article No. 33130. https://doi.org/10.1038/srep33130

[25] Marengo, J.A., et al. (2012) Extreme Climatic Events in the Amazon Basin. Theo- 
retical and Applied Climatology, 107, 73-85.

https://doi.org/10.1007/s00704-011-0465-1

[26] Marengo, J.A., et al. (2013) Recent Extremes of Drought and Flooding in Amazonia: Vulnerabilities and Human Adaptation. American Journal of Climate Change, 2, 87-96. https://doi.org/10.4236/ajcc.2013.22009

[27] Marengo, J.A., et al. (2009) Future Change of Temperature and Precipitation Extremes in South America as Derived from the PRECIS Regional Climate Modeling System. International Journal of Climatology, 29, 2241-2255.

https://doi.org/10.1002/joc. 1863

[28] De Souza, E., de Moraes, B., Ferreira, D. and Meira Filho, L.G. (2014) Dynamical Donwscaling for Railroad Areas in Eastern Amazon and Southeastern Brazil: Current Climate and Near-Future Projections. Atmospheric and Climate Sciences, 4, 155-163. https://doi.org/10.4236/acs.2014.42018

[29] Marengo, J.A. (1992) Interannual Variability of Surface Climate in the Amazon Basin. International Journal of Climatology, 12, 853-863.

https://doi.org/10.1002/joc.3370120808

[30] De Souza, E.B., Kayano, M.T. and Ambrizzi, T. (2004) The Regional Precipitation over the Eastern Amazon/Northeast Brazil Modulated by Tropical Pacific and Atlantic SST Anomalies on Weekly Timescale. Revista Brasileira de Meteorologia, 19, 113-122.

[31] Espinoza Villar, J.C., Ronchail, J., Guyot, J.L., Cochonneau, G., Naziano, F., Lavado, W., De Oliveira, E., Pombosa, R. and Vauchel, P. (2009) Spatio-Temporal Rainfall Variability in the Amazon Basin Countries (Brazil, Peru, Bolivia, Colombia, and Ecuador). International Journal of Climatology, 29, 1574-1594.

https://doi.org/10.1002/joc.1791

[32] Zhou, J. and Lau, K.-M. (1998) Does a Monsoon Climate Exist over South America? Journal of Climate, 11, 1020-1040. https://doi.org/10.1175/1520-0442(1998)011<1020:DAMCEO >2.0.CO;2

[33] Vera, C., et al. (2006) Towards a Unified View of the American Monsoon Systems. Journal of Climate, 19, 4977-5000. https://doi.org/10.1175/JCLI3896.1

[34] Carvalho, L.M.V., et al. (2004) The South Atlantic Convergence Zone: Intensity, Form, Persistence, and Relationships with Intraseasonal to Interannual Activity and Extreme Rainfall. Journal of Climate, 17, 88-108. https://doi.org/10.1175/1520-0442(2004)017<0088:TSACZI >2.0.CO;2

[35] Cohen, J.C.P., Silva Dias, M.A.F. and Nobre, C.A. (1995) Environmental Conditions Associated with Amazonian Squall Lines: A Case Study. Monthly Weather Review, 123, 3163-3174. https://doi.org/10.1175/1520-0493(1995)123<3163:ECAWAS>2.0.CO;2

[36] De Souza, E.B., et al. (2009) Precipitação sazonal sobre a Amazônia oriental no período chuvoso: Observações e simulações regionais com o RegCM3. Revista Brasileira de Meteorologia, 24, 111-124. https://doi.org/10.1590/S0102-77862009000200001

[37] Chen, M., Shi, W., Xie, P., Silva, V.B.S., Kousky, V.E., Wayne Higgins, R. and Janowiak, J.E. (2008) Assessing Objective Techniques for Gauge-Based Analyses of Global Daily Precipitation. Journal of Geophysical Research, 113, D04110. https://doi.org/10.1029/2007JD009132

[38] Wilson, S., et al. (2015) Tecnical Manual for PRECIS. The Met Office Hadley Centre Regional Climate Modelling System-Version 2.0.

https://www.metoffice.gov.uk/research/applied/international-development/precis 
[39] Jones, R., et al. (2004) Generating High Resolution Climate Change Scenarios Using PRECIS. Report, Met Office Hadley Centre, Exeter.

https://unfccc.int/files/national_reports/nonannex_i_natcom/cge/application/pdf/p recis_flyers_cop9_rcm.pdf

[40] Caesar, J., et al. (2013) Response of the HadGEM2 Earth System Model to Future Greenhouse Gas Emissions Pathways to the Year 2300. Journal of Climate, 26, 3275-3284. https://doi.org/10.1175/JCLI-D-12-00577.1

[41] Van Vuuren, D.P., et al. (2011) The Representative Concentration Pathways: An Overview. Climatic Change, 109, 5-31. https://doi.org/10.1007/s10584-011-0148-z

[42] McKee, T.B., Doesken, N.J. and Kleist, J. (1993) The Relationship of Drought Frequency and Duration to Time Scales. In: Proceedings of the Eighth Conference on Applied Climatology, American Meteorological Society, Boston, 179-184.

[43] Santos, S.R.Q., et al. (2017) Determinação de Regiões Homogêneas do Índice de Precipitação Normalizada (SPI) na Amazônia Oriental. Revista Brasileira de Meteorologia, 32, 111-122. https://doi.org/10.1590/0102-778632120160013

[44] World Meteorological Organization (2012) Standardized Precipitation Index: User Guide. https://library.wmo.int/doc_num.php?explnum_id=7768

[45] Ferreira, D.B.S., De Souza, E.B. and De Oliveira, J.V. (2020) Identificação de extremos de precipitação em municípios do estado do Pará e sua relação com os modos climáticos atuantes nos oceanos Pacífico e Atlântico. Revista Brasileira de Climatologia, 16, 197-222.

[46] Costa, C.P.W., et al. (2019) Avaliação de simulação histórica da precipitação e temperatura no Leste da Amazônia utilizando um modelo de alta resolução. Revista Brasileira de Climatologia, 25, 612-642. https://doi.org/10.5380/abclima.v25i0.57690

[47] Alves, L.M. and Marengo, J.A. (2010) Assessment of Regional Seasonal Predictability Using the PRECIS Regional Climate Modeling System over South America. Theoretical and Applied Climatology, 100, 337-350. https://doi.org/10.1007/s00704-009-0165-2

[48] Alves, L.M., Marengo, J.A., Fu, R. and Bombardi, R.J. (2017) Sensitivity of Amazon Regional Climate to Deforestation. American Journal of Climate Change, 6, 75-98. https://doi.org/10.4236/ajcc.2017.61005

[49] Moraes, B.C., et al. (2005) Variação espacial e temporal da precipitação no estado do Pará. Acta Amazonica, 35, 207-214. https://doi.org/10.1590/S0044-59672005000200010

[50] Alexander, L.V., et al. (2006) Global Observed Changes in Daily Climate Extremes of Temperature and Precipitation. Journal of Geophysical Research, 111, 1-22. 